\title{
Effect of Curcumin on Astrogliosis and Improvement of Behavioral Movement in Acute Phase of Spinal Cord Injury in a Contusion Model of Rat
}

\author{
Parastoo Barati Dowom $^{1,2}$, Marzieh Darvishi ${ }^{2,3}$, Mohammad Jabbarian' ${ }^{1}$, Azam Babakhani ${ }^{1}$, Kambiz Roshanaei ${ }^{\text {* }}$ \\ ${ }^{1}$ Department of Physiology, Faculty of Sciences, Qom Branch, Islamic Azad University, Qom, Iran \\ ${ }^{2}$ Shefa Neuroscience Research Center, Khatam Alanbia Hospital, Tehran, Iran \\ ${ }^{3}$ Department of Anatomy, Faculty of Medicine, Ilam University of Medical Sciences, Ilam, Iran
}

\section{A BSTRACT}

Introduction: Any traumatic spinal cord injury (SCI) may cause symptoms ranging from pain to complete loss of motor and sensory functions below the level of the injury. Despite of many advances in surgical techniques, treatment of SCI remains as a complex issue. Reduction of the initial inflammatory processes by creation of framework is suggested as a possible novel treatment. The aim of this study was evaluation of the effect of curcumin on the improvement of behavioral movement in rat contusion model in acute phase. Materials and Methods: In this in vivo study, rats were randomly assigned to experimental, laminectomy, sham operated (normal saline injected) and treatment groups. In treatment groups, the rats received daily intraperitoneal injection of curcumin $(70,60,50$, or $40 \mathrm{mg} / \mathrm{ml} / \mathrm{kg})$ at $6 \mathrm{~h}$ after the SCI. Spinal cord injury was performed by a standard procedure. After shaving, laminectomy was performed at T12-L1 level and the exposed spinal cord was exposed a 10 gram metal rod with a $2 \mathrm{~mm}$ diameter dropped from a height of $25 \mathrm{~mm}$. The locomotor function was assessed by Basso-Beattie-Bresnahan (BBB) test for 12 weeks. Three months after SCI, the spinal cords were evaluated by morphometric, glial fibrillary acid protein (GFAP) expression, and the axonal regeneration. Results: Immunohistochemical staining and BBB test scores of spinal cord injured rats treated with curcumin were significantly improved at day 7 compared to sham rats. The level of GFAP was significantly decreased in curcumin treated group compared to sham group. Optimal dose of curcumin was $60 \mathrm{mg} / \mathrm{ml} / \mathrm{kg} 6 \mathrm{~h}$ after SCI. Conclusion: The data demonstrate that curcumin improves behavioral movement in acute phase of SCI, possibly via the enhancement of axonal regeneration and reduction of astrogloisis.

\section{Key words:}

1. Curcumin

2. Spinal Cord Injuries

3. Rats

*Corresponding Author: Kambiz Roshanaei

E-mail: kambizroshanaei@gmail.com

doi: 10.18869/acadpub.shefa.5.1.18 
اثر كوركومين بر آستروكليوزيس و بهبود رفتار حركتى در مرحلة حاد آسيب طناب نخاعى در يك مدل كانتيورن موش صحرايى

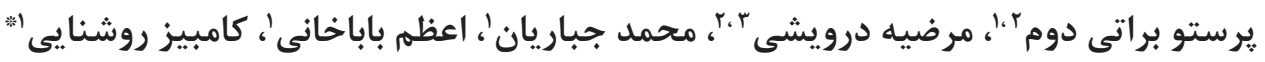 \\ امروه فيزيولوزى، دانشكده علوم، واحد قم، دانشعاه آزاد اسلامى، قم، ايران \\ rمركزتحقيقات علوم اعصاب شفا، بيمارستان خاتمالانبياء، تهران، ايران \\ "كروه آناتومى، دانشكده يزشكى، دانشعاه علوم يزشكى ايلام، ايلام، ايران
}

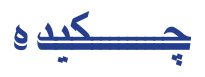

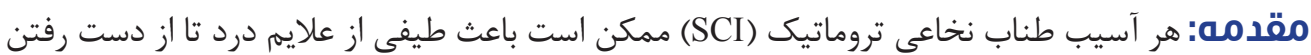

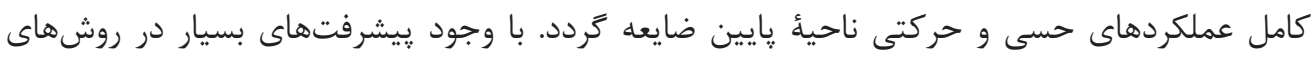

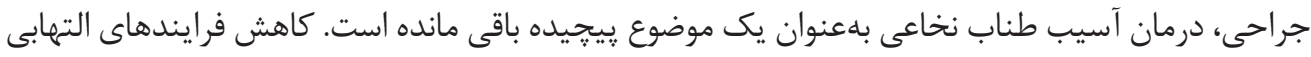

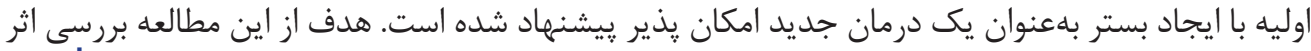

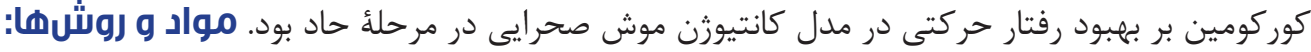

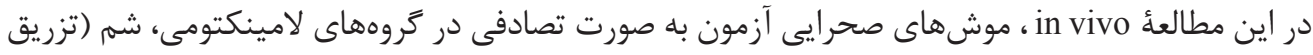

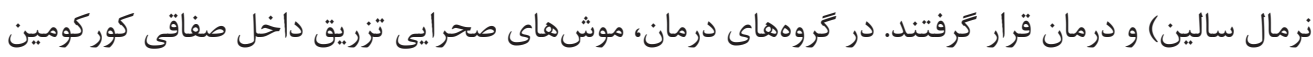

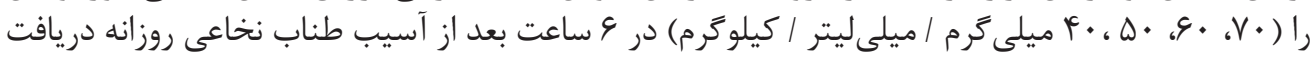

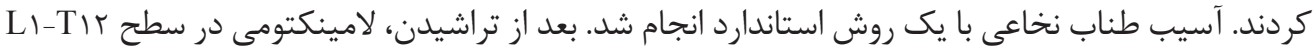

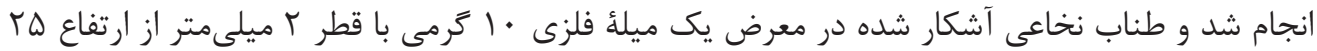

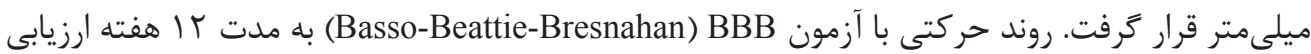

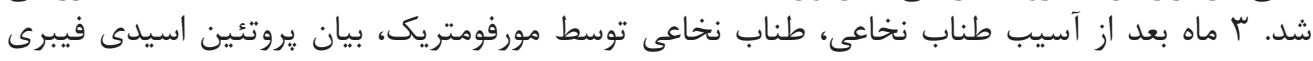

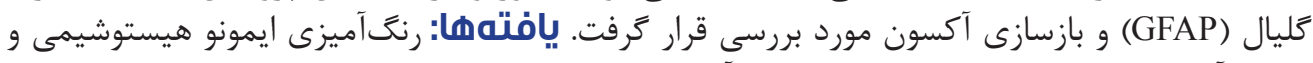

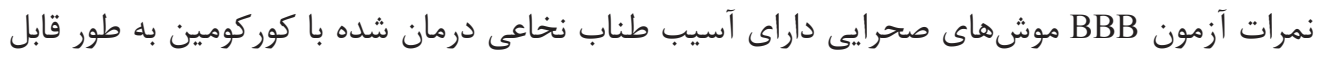

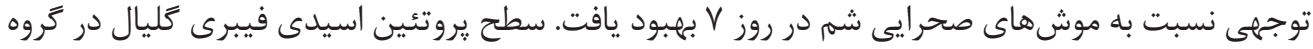

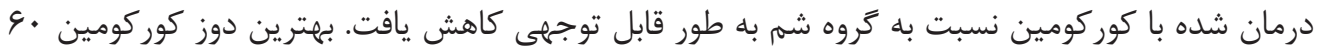

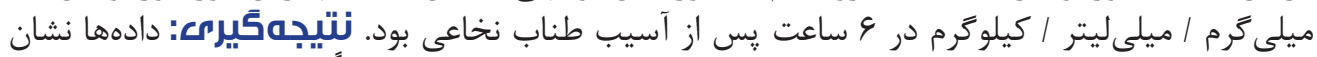

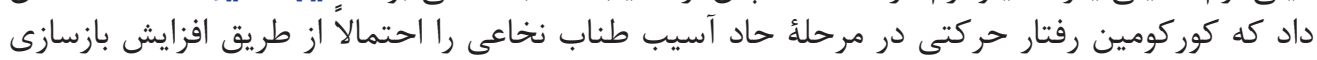
آكسون و كاهش كورمين رفترار حركنى در مرحليوزيس بهبود مىبخشد.

:

" نويسنده مسئول: كامبيز روشنايى آدرس الكترونيكى: kambizroshanaei@gmail.com 


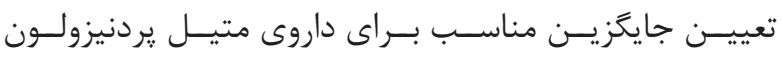

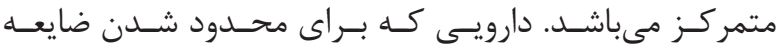

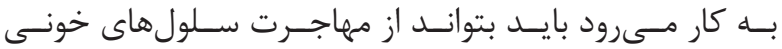

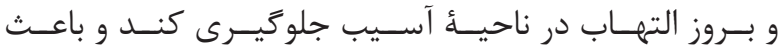

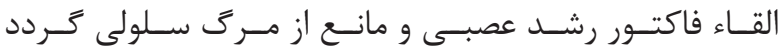

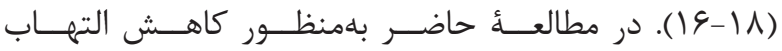

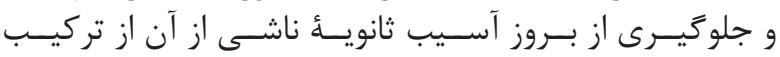

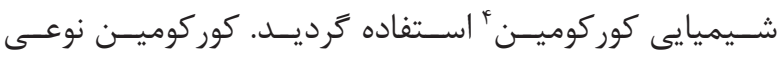

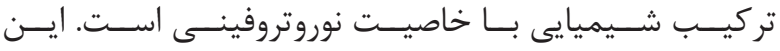

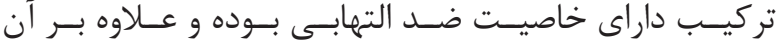

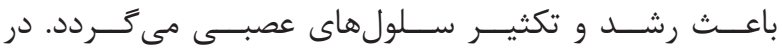

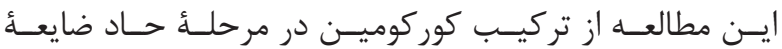

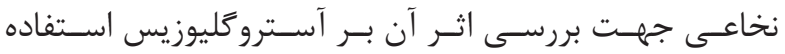

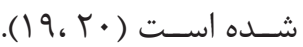

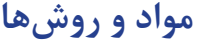

ا. تزريق كوركومين به مدلهاى كانتيوثن مورد آزمون

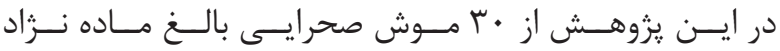

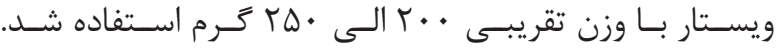

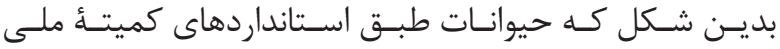

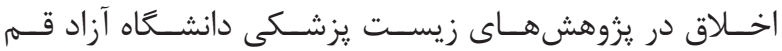

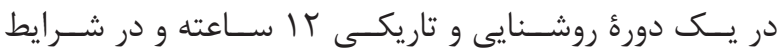

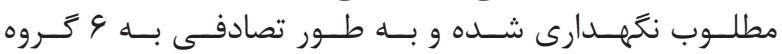

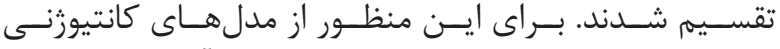

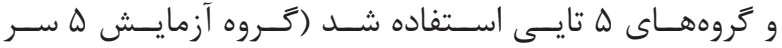

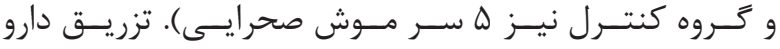

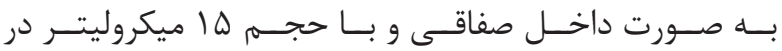

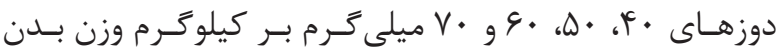

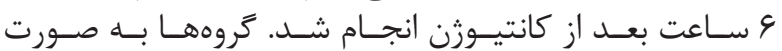

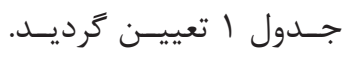

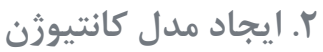

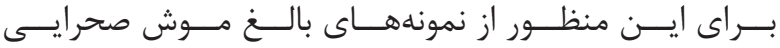

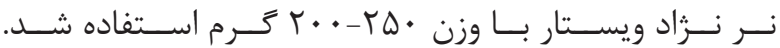

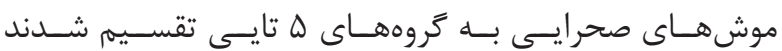

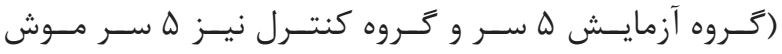
صحرايسى).

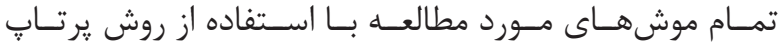

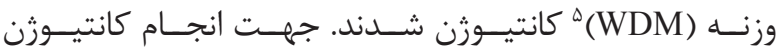

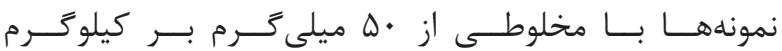

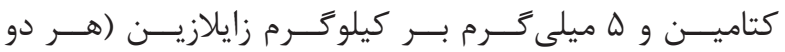

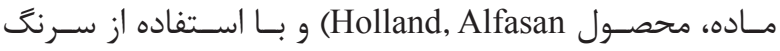

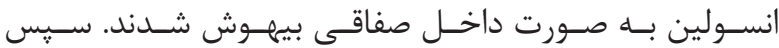

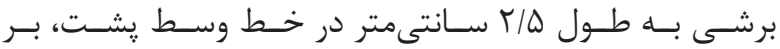

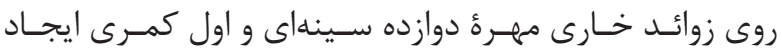

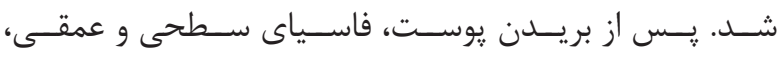

${ }^{1}$ Spinal cord injury

${ }^{2}$ Morphology

${ }^{3}$ Glial fibrillary acidic protein

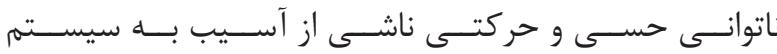

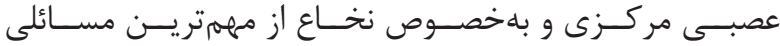

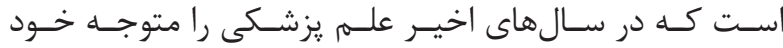

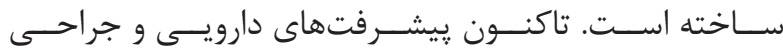

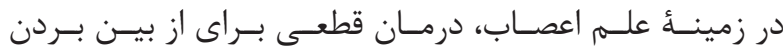

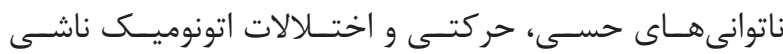

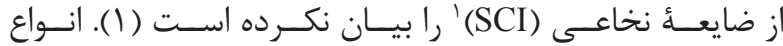

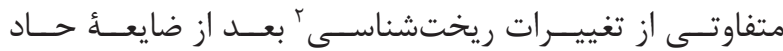

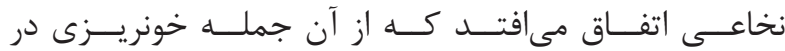

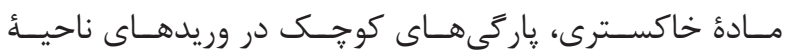

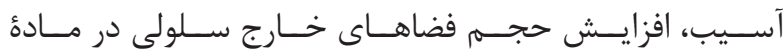

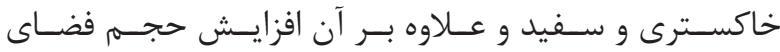

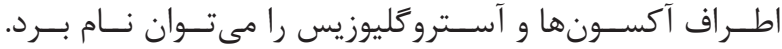

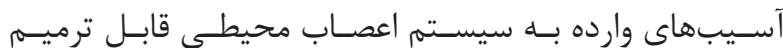

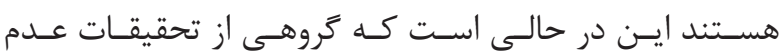

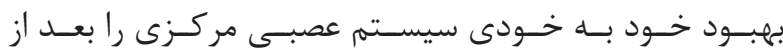

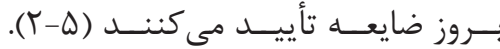

علـت نقـص در ترميـهم ناحيـهُ آسـيب ديـده در ايسـن مــوارد

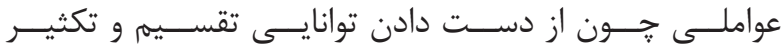

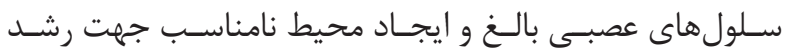

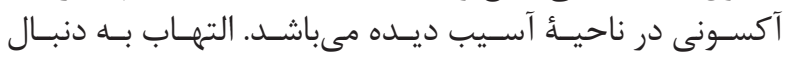

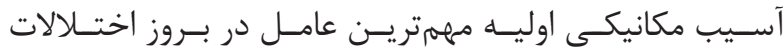

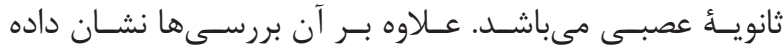

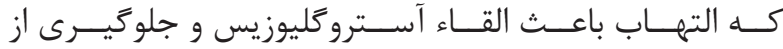

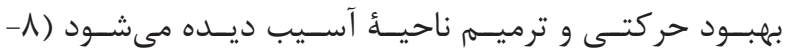

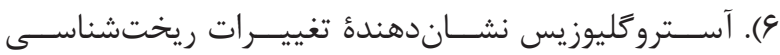

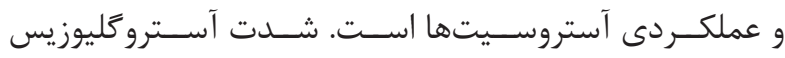

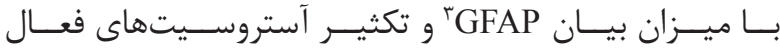

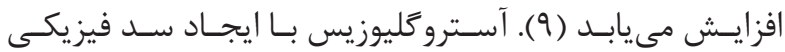

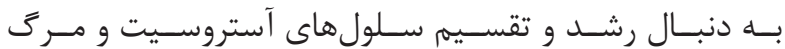

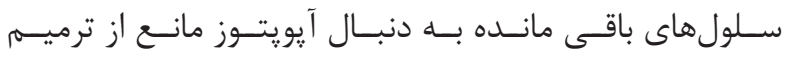

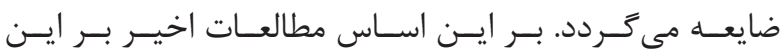

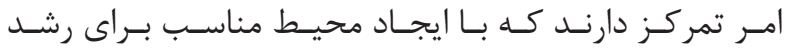

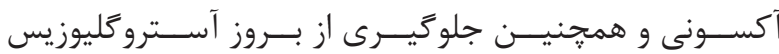

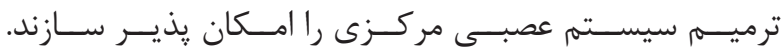

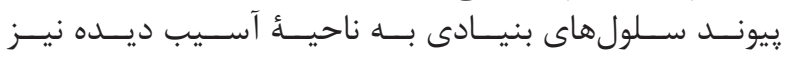

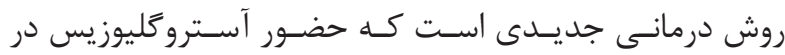

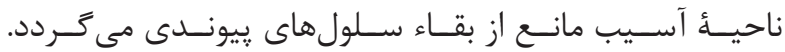

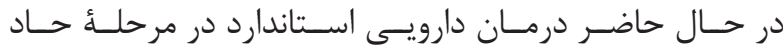

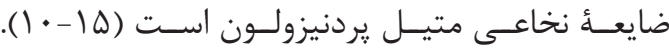

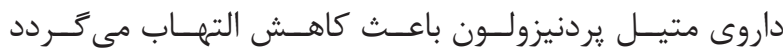

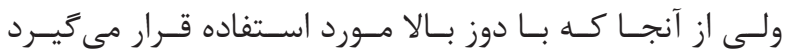

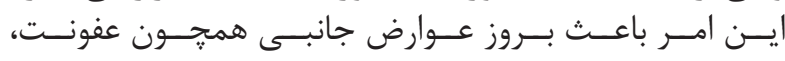

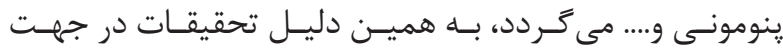

${ }^{4}$ Curcumin

${ }^{5}$ Weight drop method 
جدول ا- طراحى گروههاى مطالعُ كوركومين.

\begin{tabular}{|c|c|c|c|c|}
\hline كروهها & ت تعداد نمونه & آسيب نخاعى & دوز دارو & ساعت تززيق بعد از آسيب \\
\hline 1 & $\Delta$ & فتط لامينكتومى & - & - \\
\hline r & $\Delta$ & كانتيورثن (درهان نشده) & سالين & - \\
\hline r & $\Delta$ & كانتيوزن & كوزكومين · + ميلى كرم & 9 اعت \\
\hline r & $\Delta$ & كانتيوزن & كوركومين · ه ميلى كرم & 9 \\
\hline$\Delta$ & $\Delta$ & 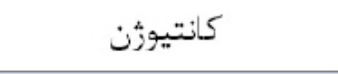 & كور كومين ·و ميلى & 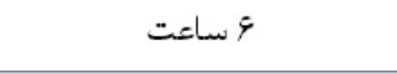 \\
\hline 9 & $\Delta$ & كانتيوزن & كوركومين · V ميلى كرم & 9 اعت \\
\hline
\end{tabular}

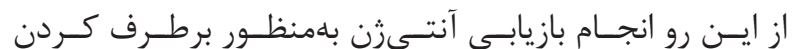

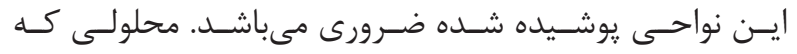

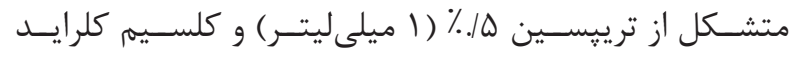

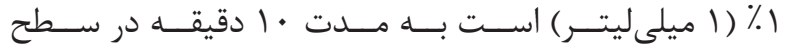

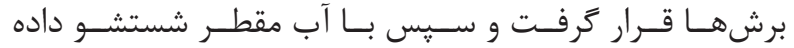

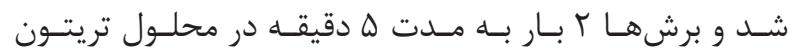
• • X

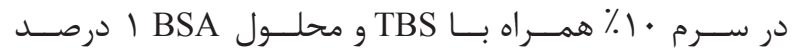

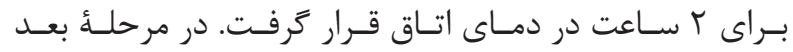

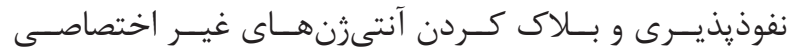

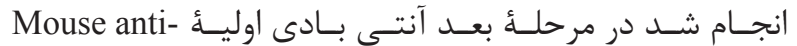
(Millipore, Germany) GFAP monoclonal antibody

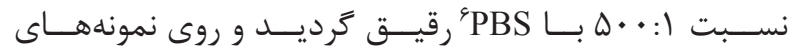

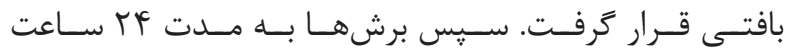

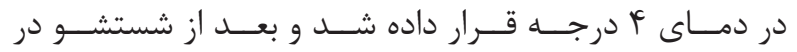

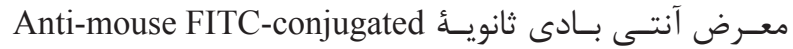
Anti-mouse conjugated with g (Millipore, Germany) قـــــ (Invitrogen, Germany) peroxidase

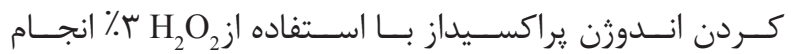

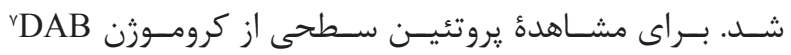

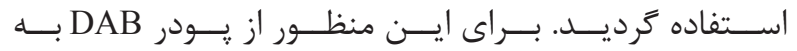

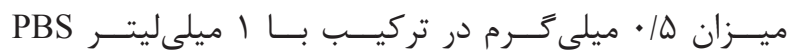

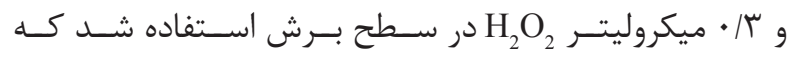

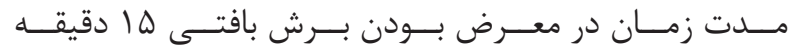

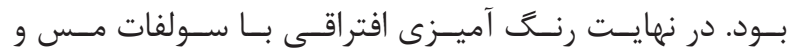

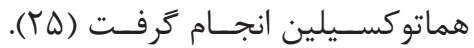
تجزيه و تحليل دادهها

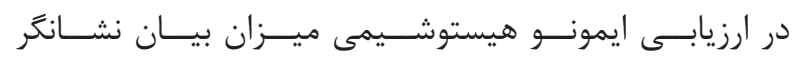
GFAP

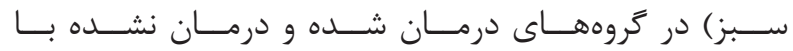

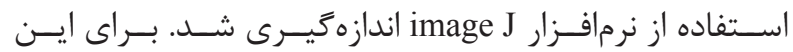

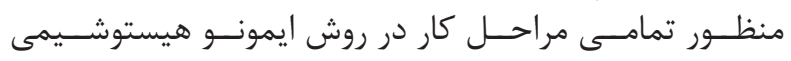

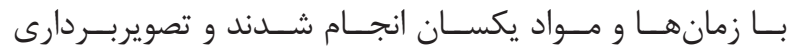

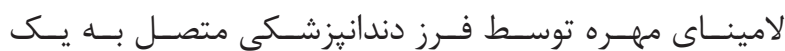

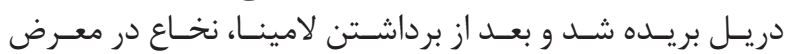

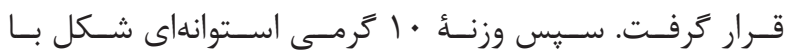

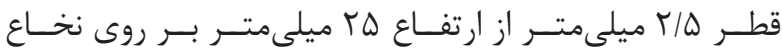

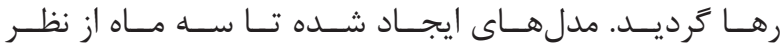

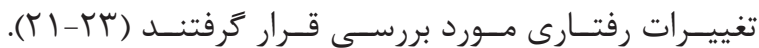
س. ارزيابى حركتى با روش BBB

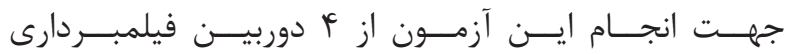

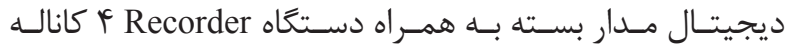

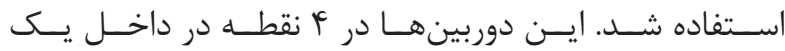

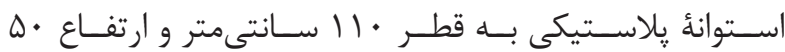

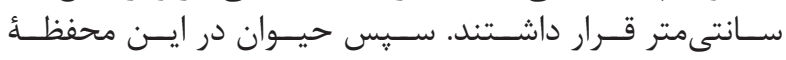

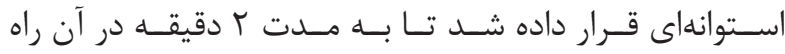

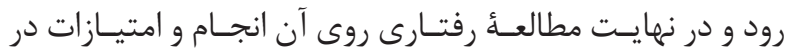

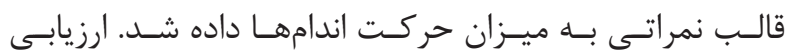

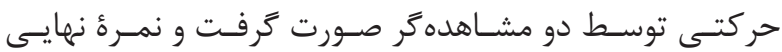

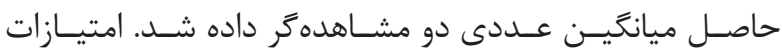

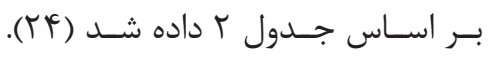

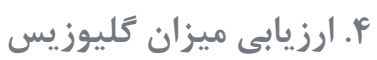

\section{بررسى نشانگر GFAP با روش ايمونو هيستوشيمى} DAB , FITC

بـراى ايـن منظــور از نشـانغر اختصاصـى GFAP اسـتفاده شـد.

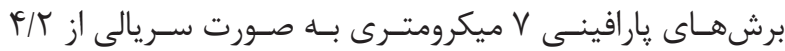

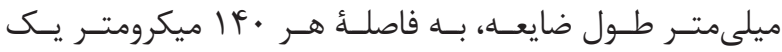

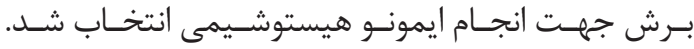

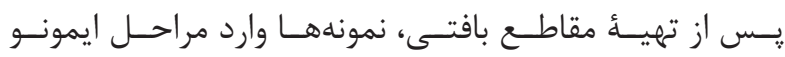

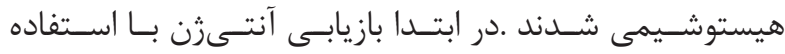

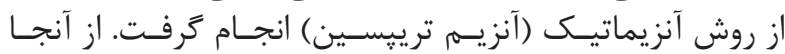

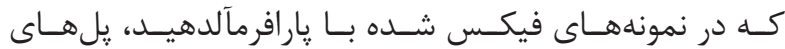

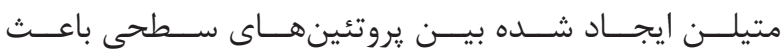

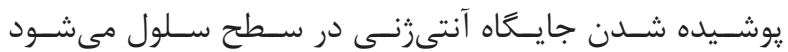

${ }^{6}$ Phosphate buffered saline

${ }^{7}$ Diamino benzidine 


\begin{tabular}{|c|c|}
\hline نؤوع حركت اندام خلفى & امتياز \\
\hline مددم مشامدة حركت در مفاصل الدام حلفى & + \\
\hline 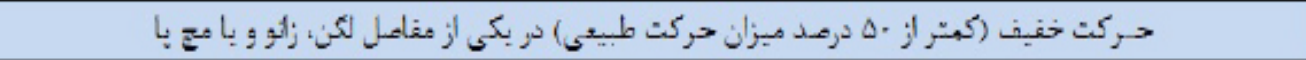 & 1 \\
\hline 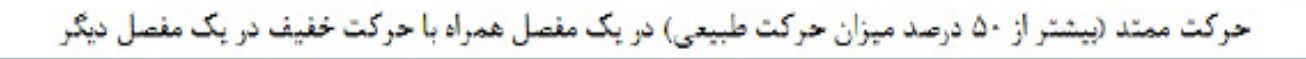 & r \\
\hline حركت ميتد و كثيده در نو مفصل & $r$ \\
\hline حركت خفيف در سف مغصل (لكئ، زائو و متج) الدام خلفى & + \\
\hline حركت خفبف در نو مفصل و حركت هميّد در مفصل سوم & $\Delta$ \\
\hline حركت ميتد در نو مفصل و حركت لخفيف در مثصل سوم & 8 \\
\hline مركت ميتد در هر سل مغتصل & r \\
\hline 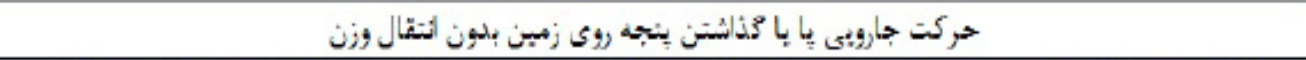 & A \\
\hline كذانشتن مهتد يا هتناوب بنجه روى زهين با أثقال وزن و يا كاهى حيوان وزن خود را روى بشت بنجه نحمل ثىكثد & 9 \\
\hline 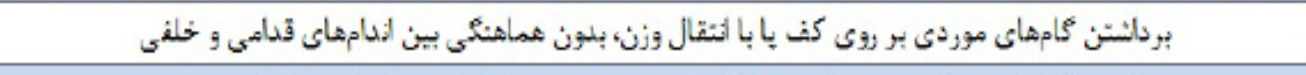 & 1. \\
\hline 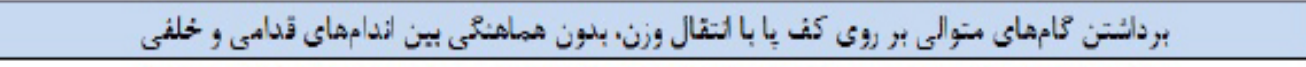 & 11 \\
\hline 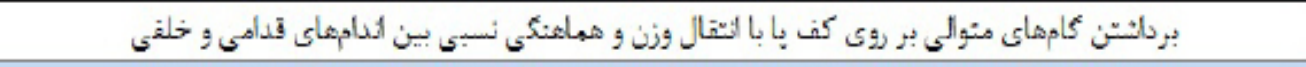 & ir \\
\hline 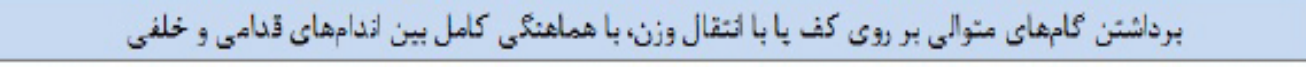 & 14 \\
\hline 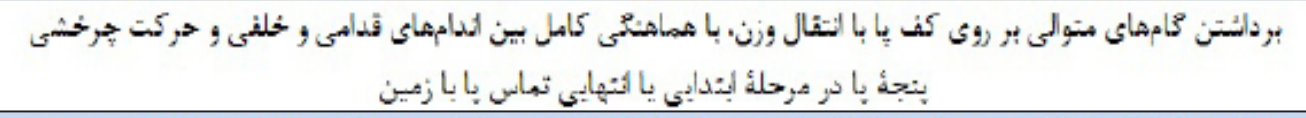 & if \\
\hline 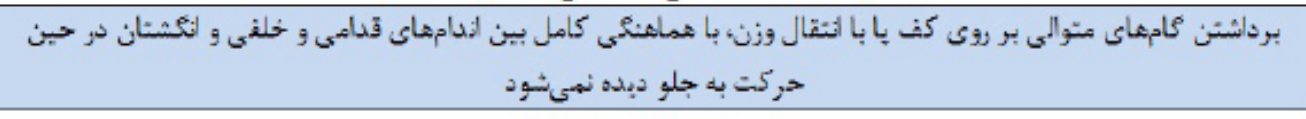 & 10 \\
\hline 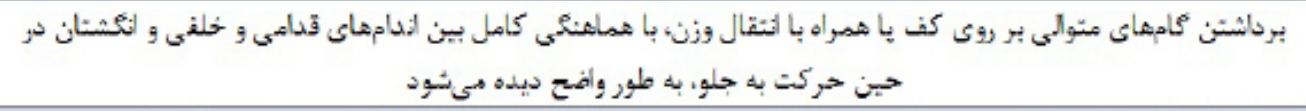 & 18 \\
\hline 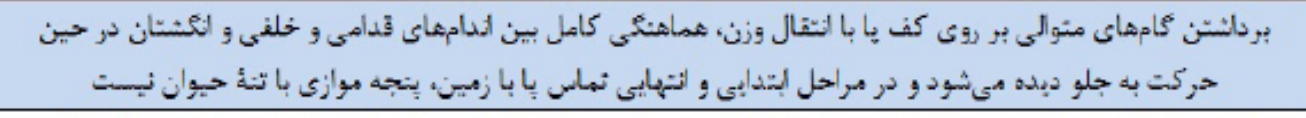 & iv \\
\hline 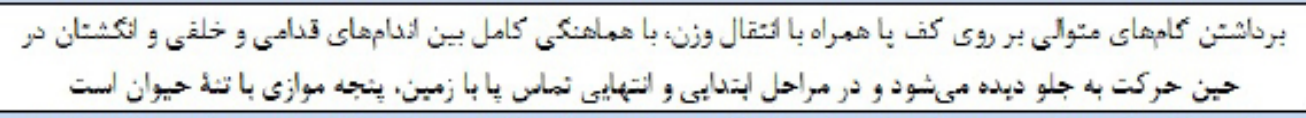 & M \\
\hline 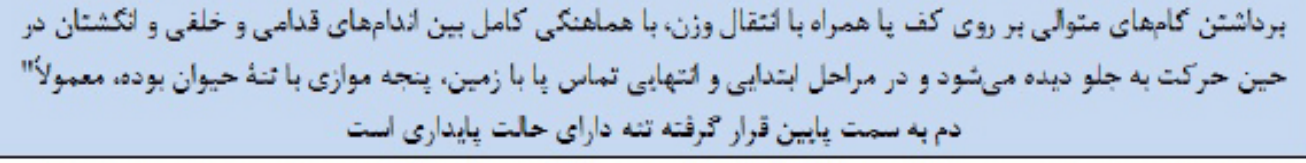 & 19 \\
\hline 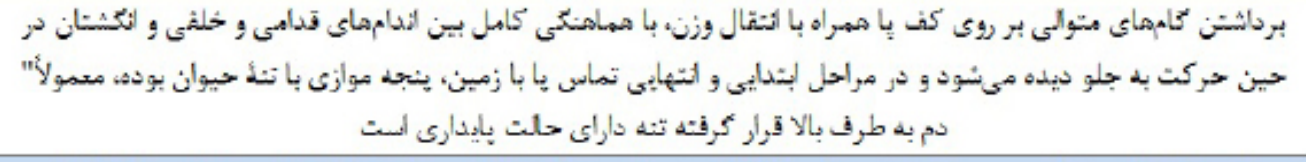 & $r$. \\
\hline 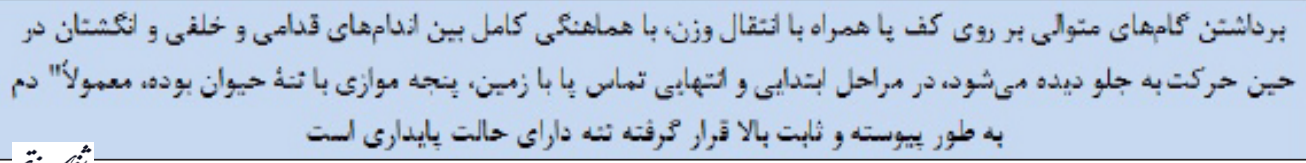 & Yl \\
\hline
\end{tabular}

كرفـت. سـطح معنسى دارى ه•|•>P در نظــر خرفتــه شــد.

يافتهها

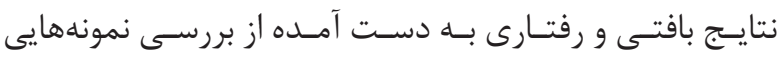

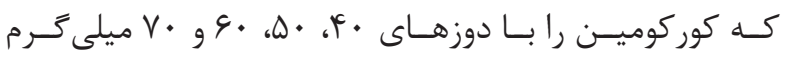

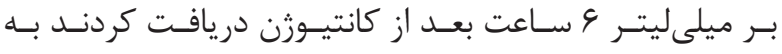

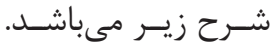

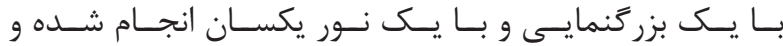

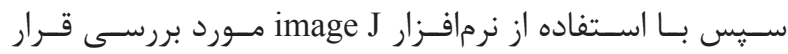

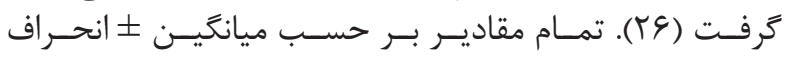

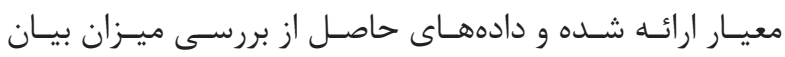

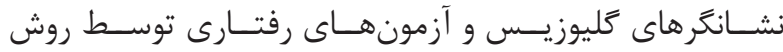

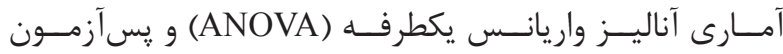

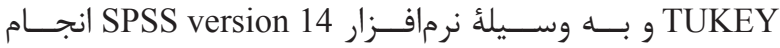


نتايج حاصل از ارزيابى آسيب بافتى بين گروههاى مورد آزمون

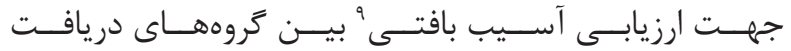

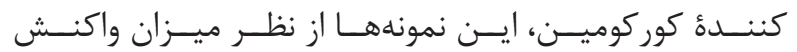

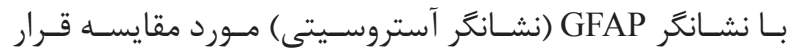

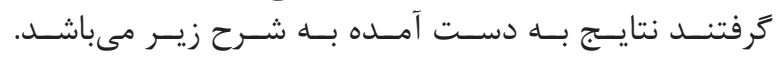
نتايج به دست آمده از بررسى نشانگر GFAP با روش ايمونو هيستوشيمى به

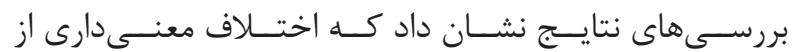

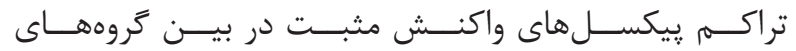

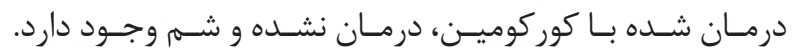

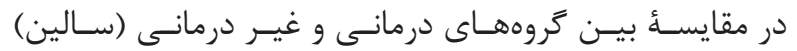

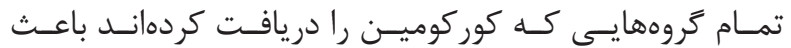

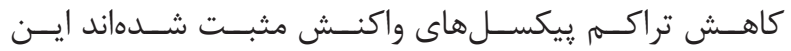

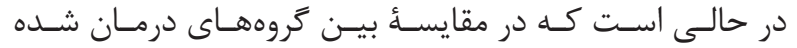

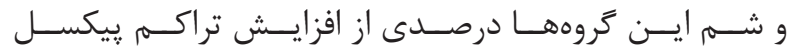

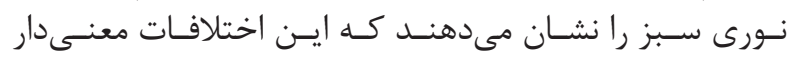

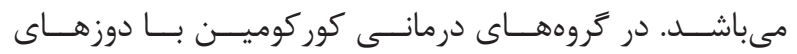

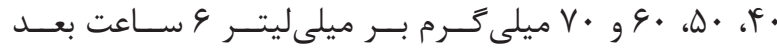

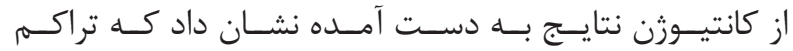
ييكسـل نـورى بــ ترتيـب مريسوط/

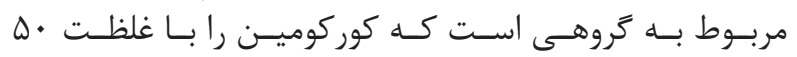

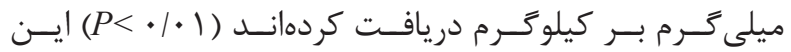

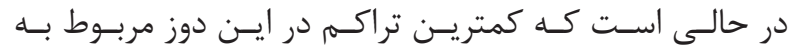

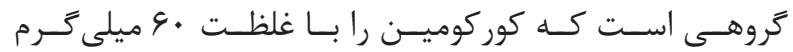

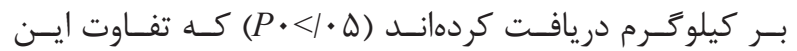

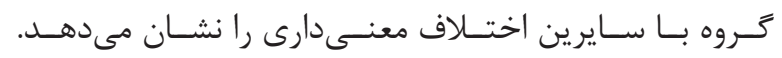

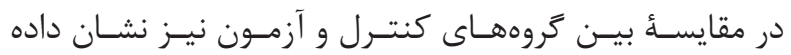

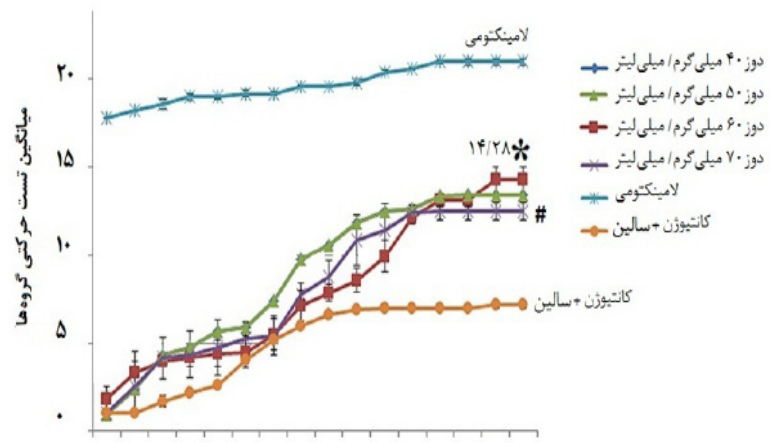

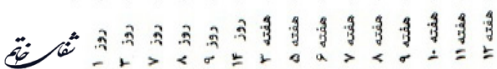

زمان آزمون

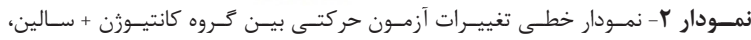

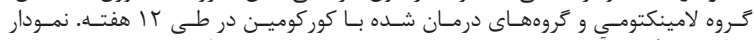

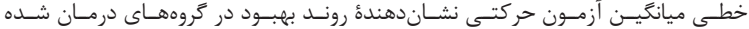

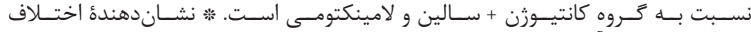

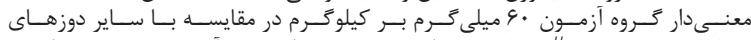

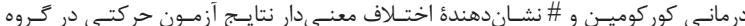

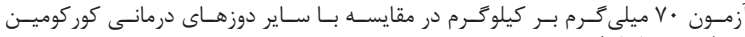

${ }^{8}$ Basso-beattie-bresnahan

${ }^{9}$ Histopathology
نتايج ارزيابى حركتى در زروههاى درمانى كوركومين با استفاده از آزمون رفتارى BBB

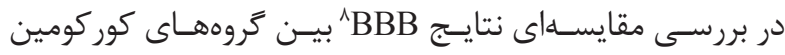

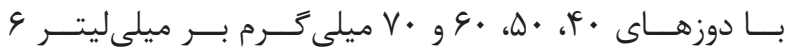

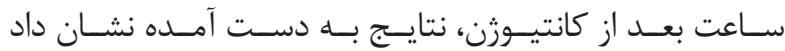

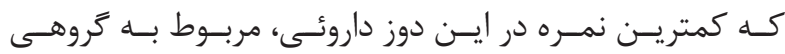

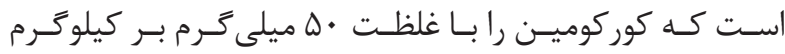

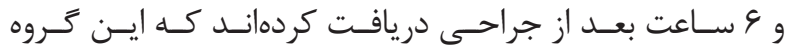

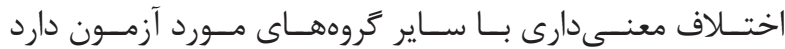

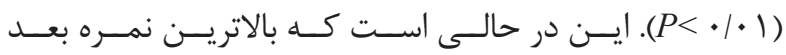

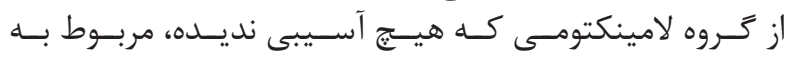

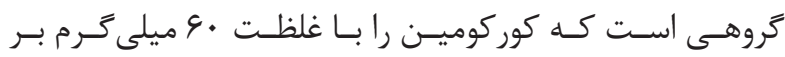

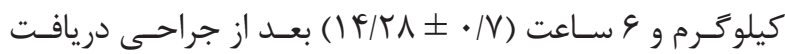

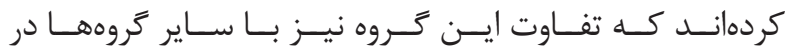

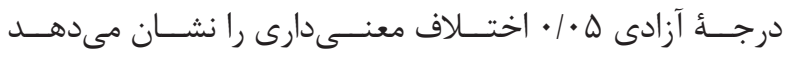

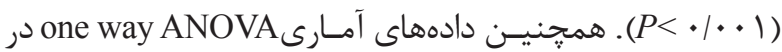

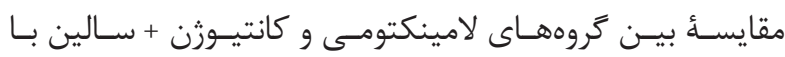

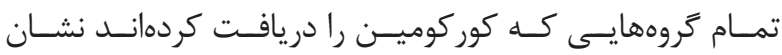

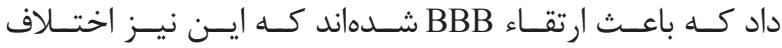

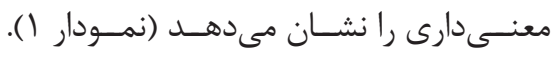

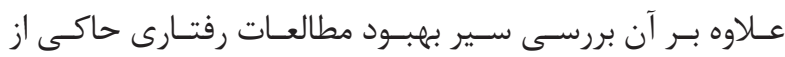

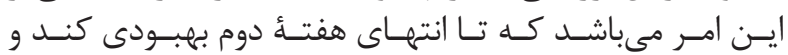

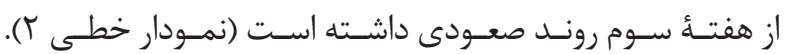

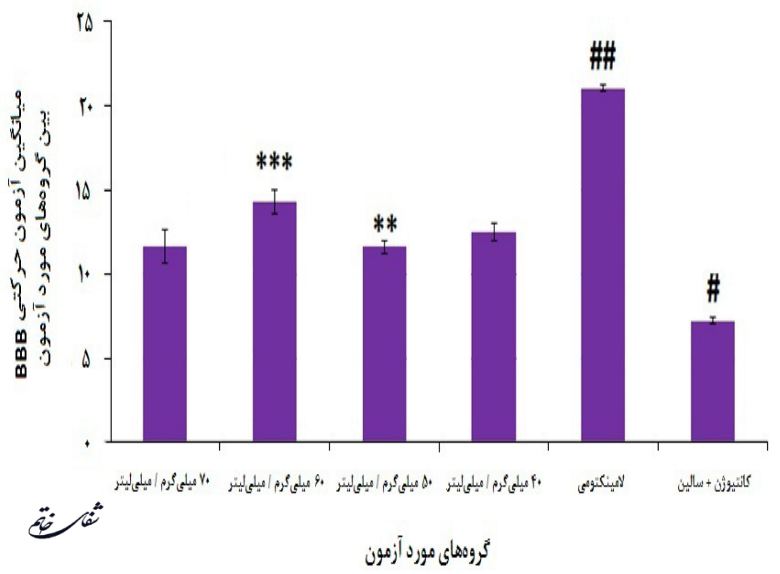

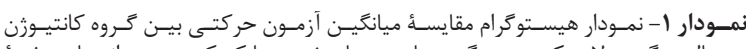

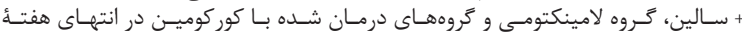

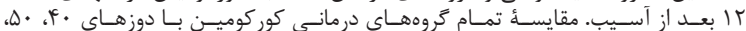

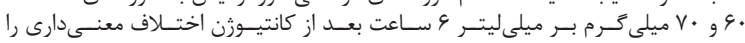

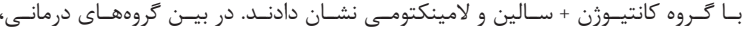

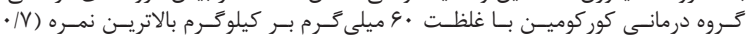

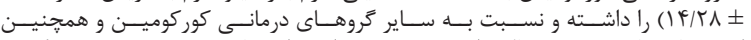

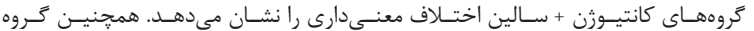

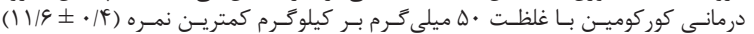

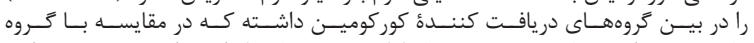

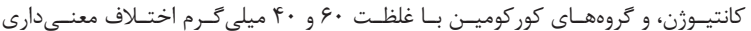

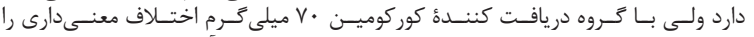

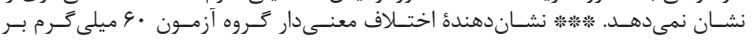

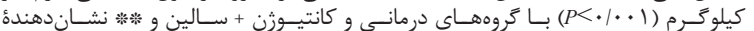

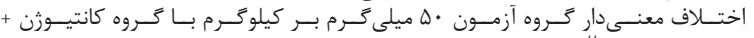

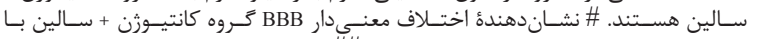

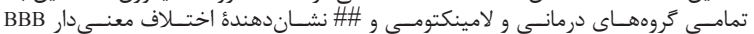

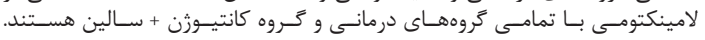




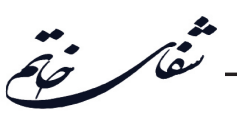

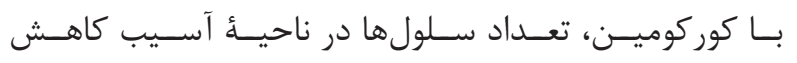

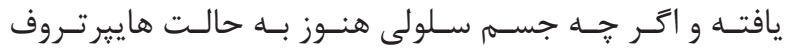

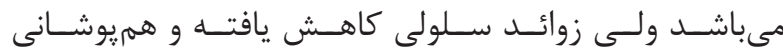

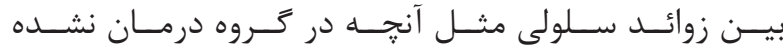

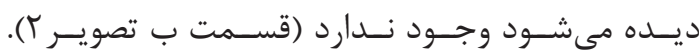

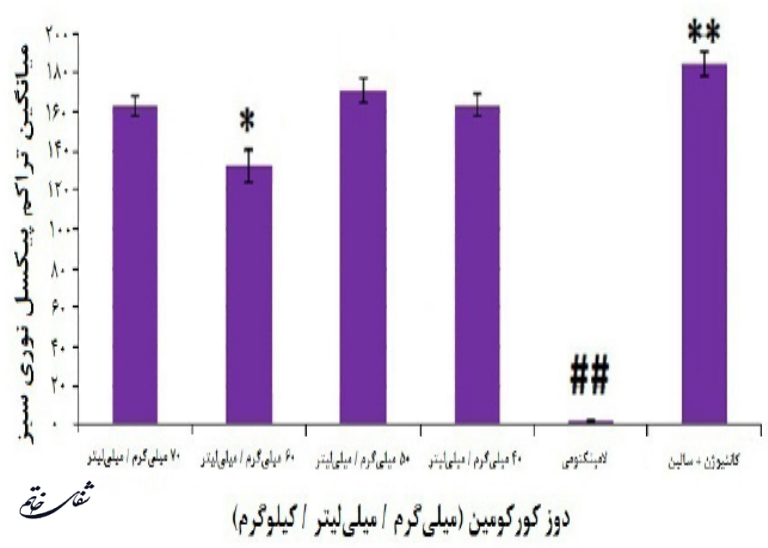

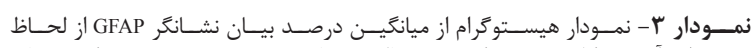

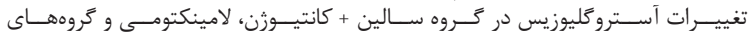

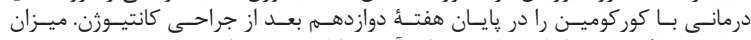

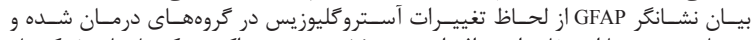

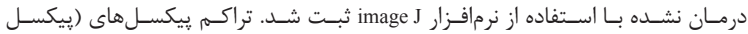

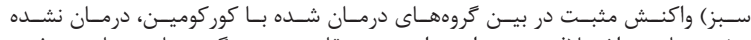

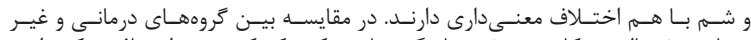

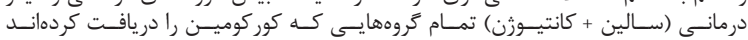

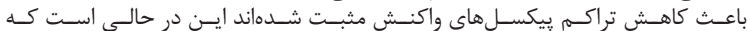

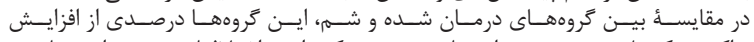

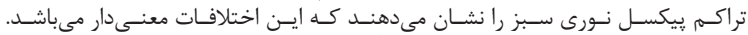

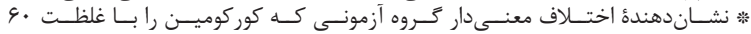

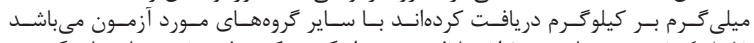

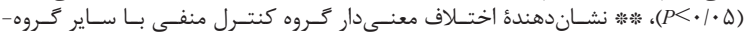

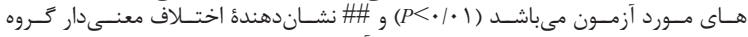
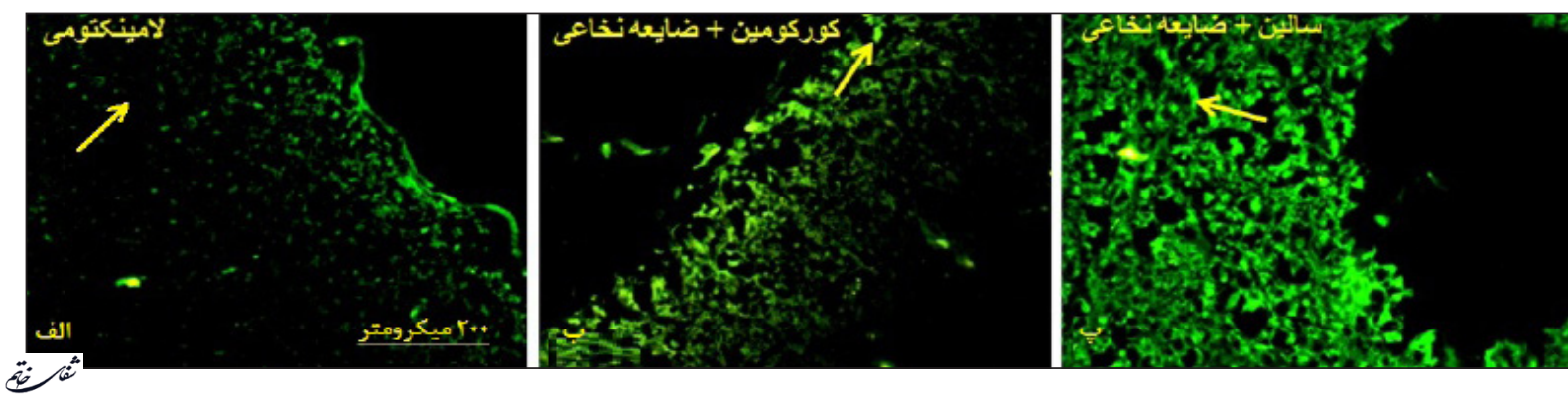

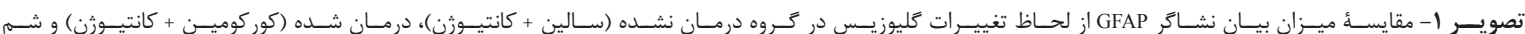

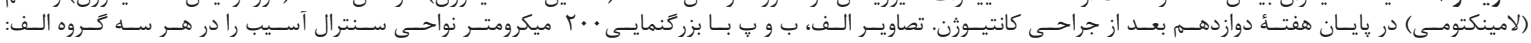

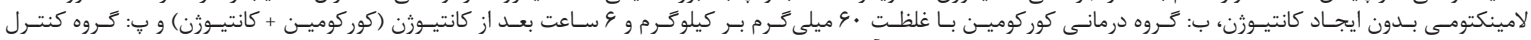

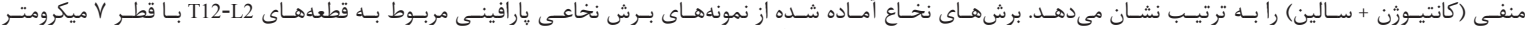

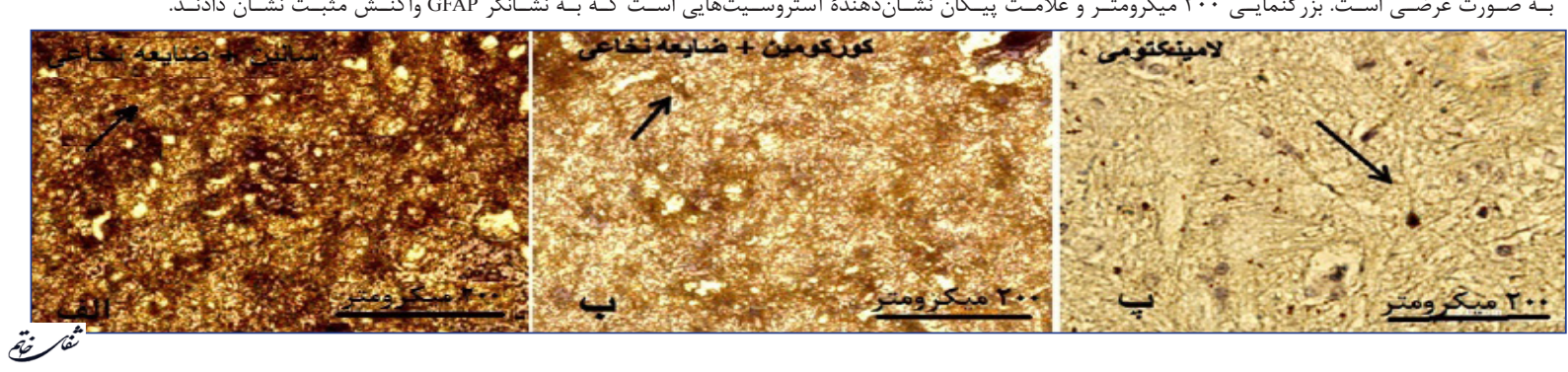

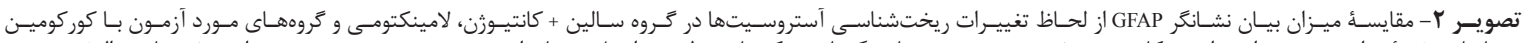

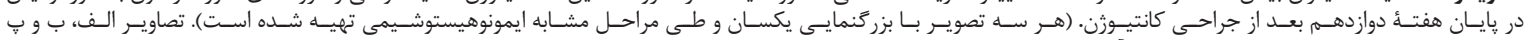

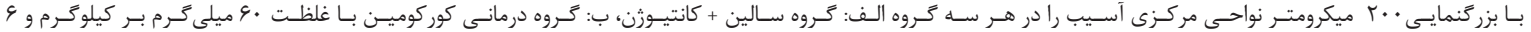

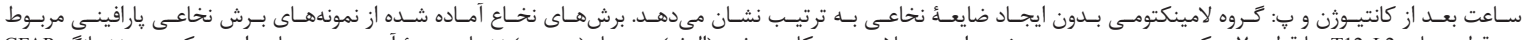

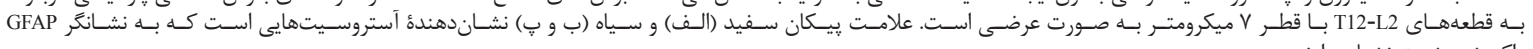




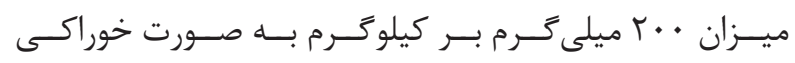

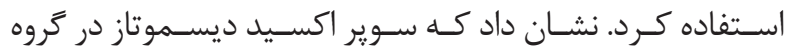

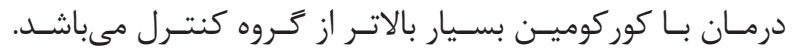

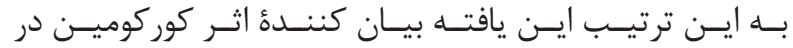

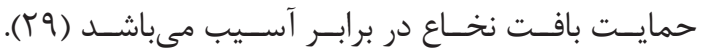

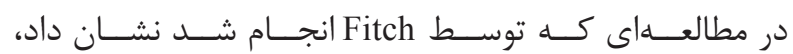

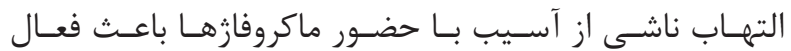

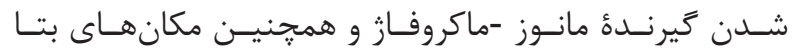

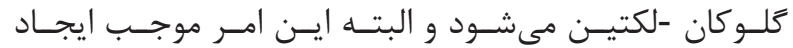

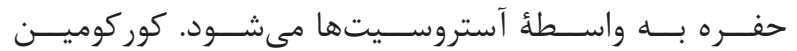

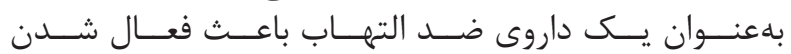

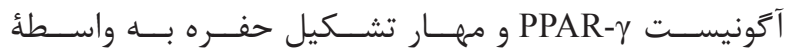

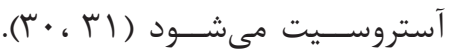

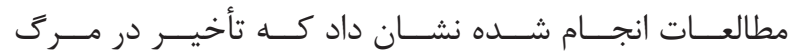

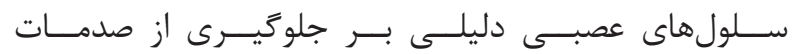

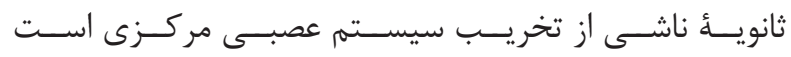

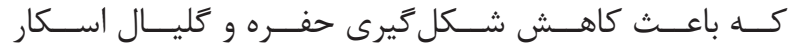

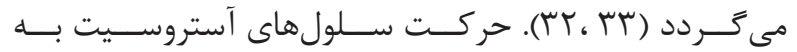

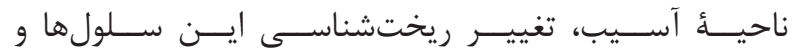

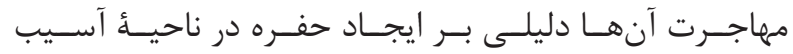

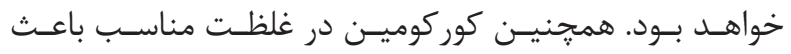

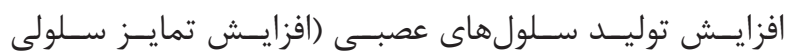
از طريـق مسـير/AAK)/Stat3, Wnt/b-catenin, PI3K

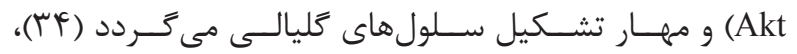

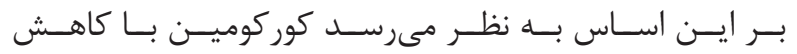

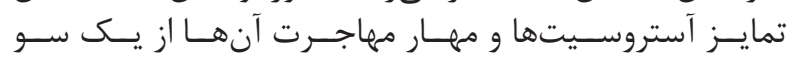

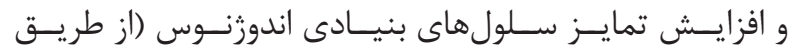

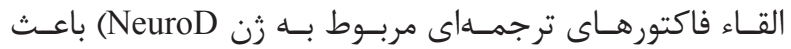

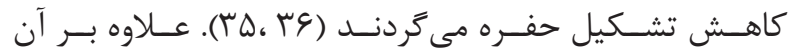

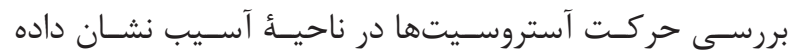

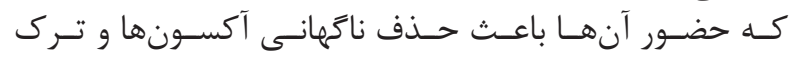

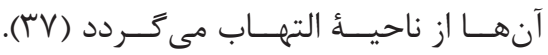

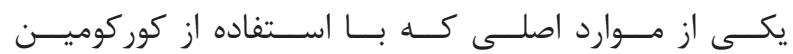

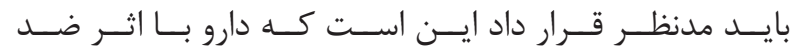

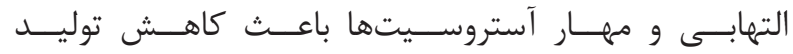

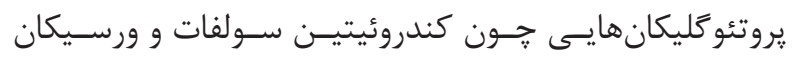

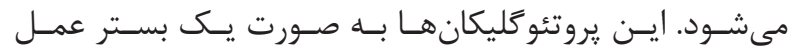

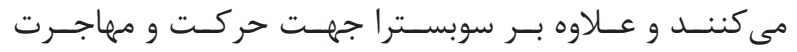

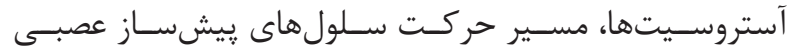

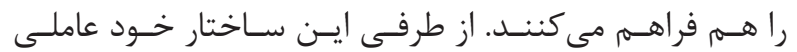

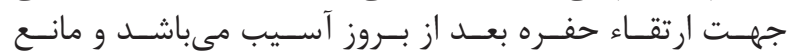

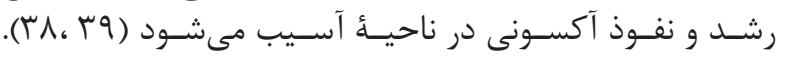

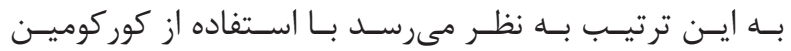

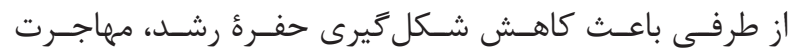

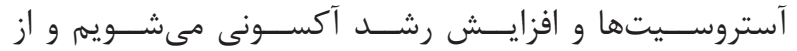

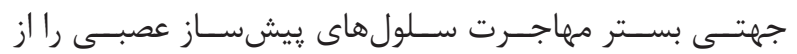

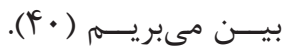

بحث و نتيجهَ كيرى

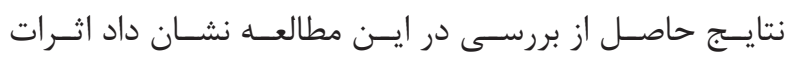

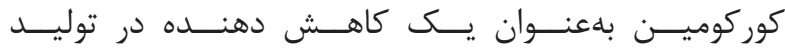

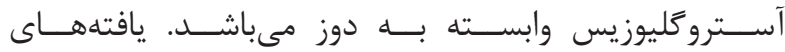

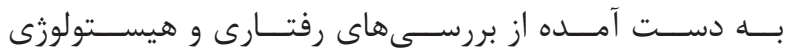

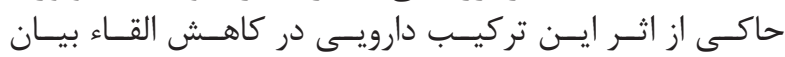

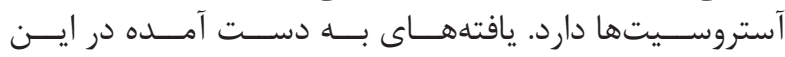

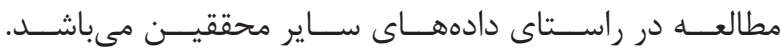

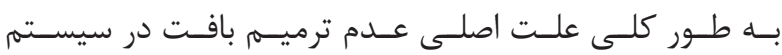

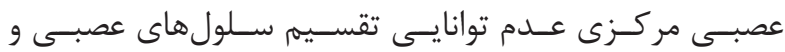

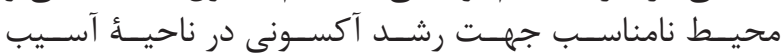

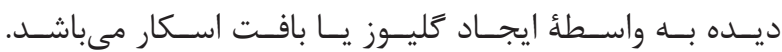

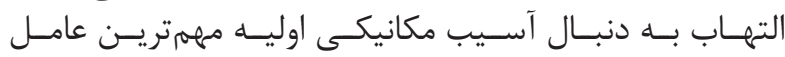

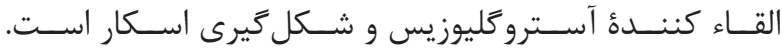

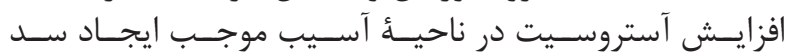

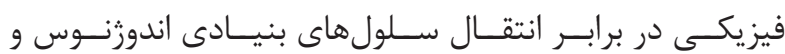

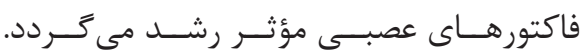

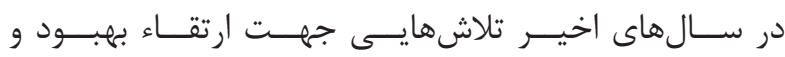

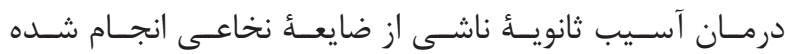

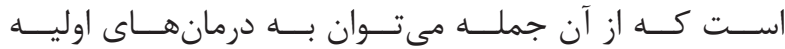

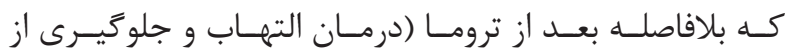

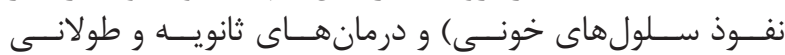

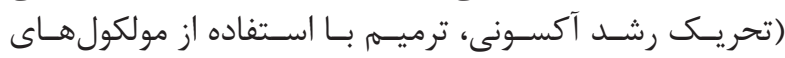

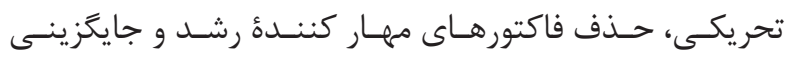

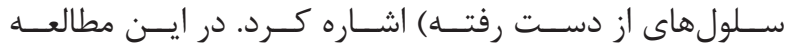

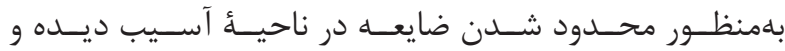

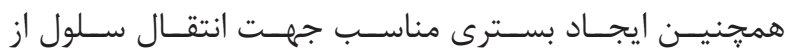

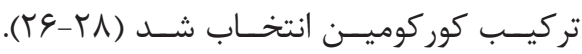

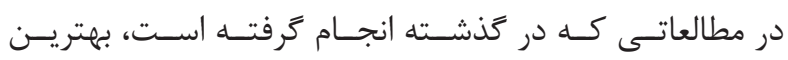

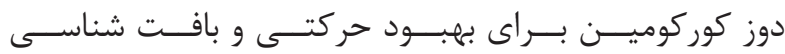

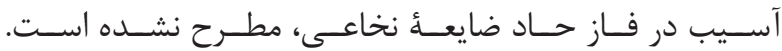

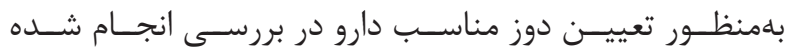

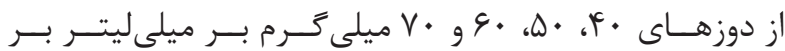

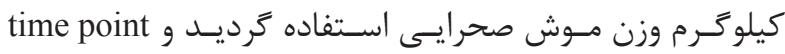

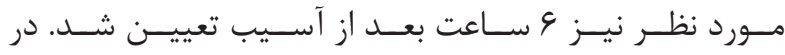

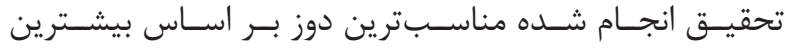

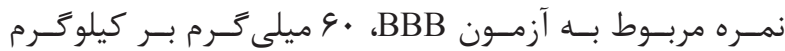

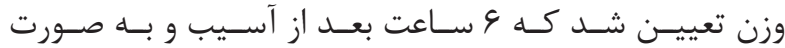

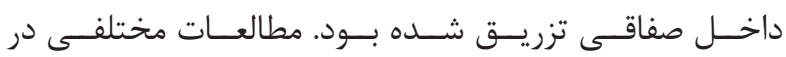

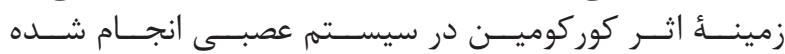

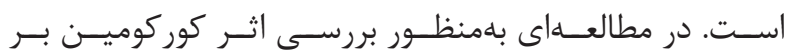

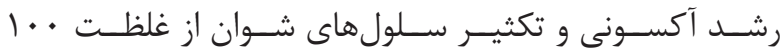

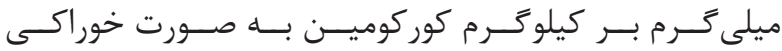

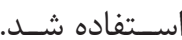

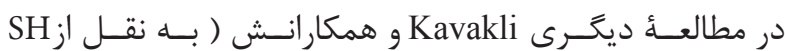

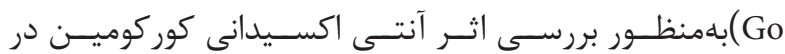

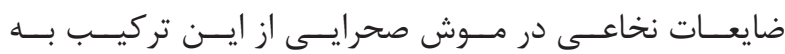




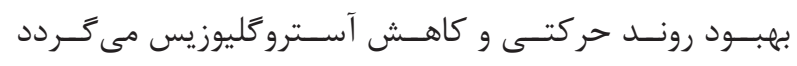

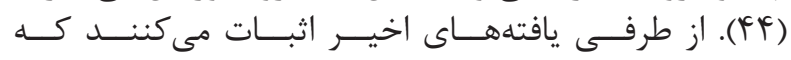

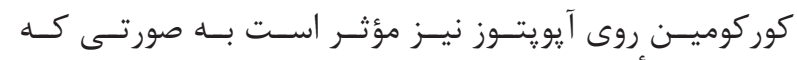

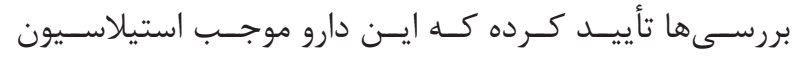

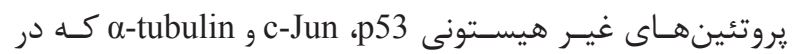

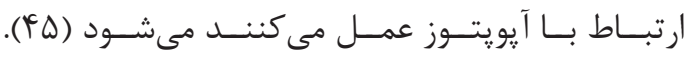

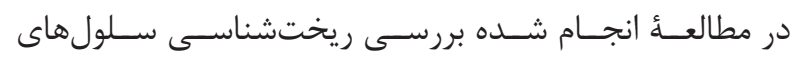

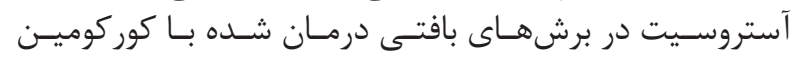

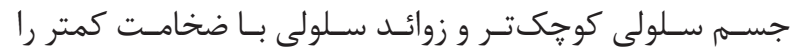

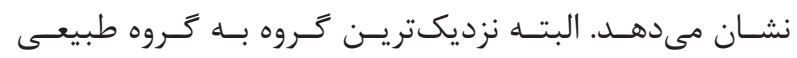

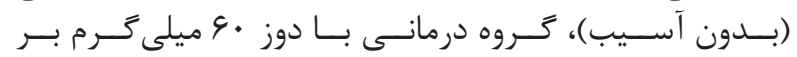

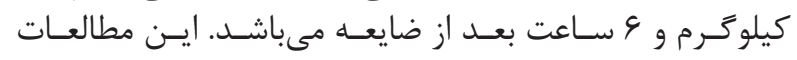

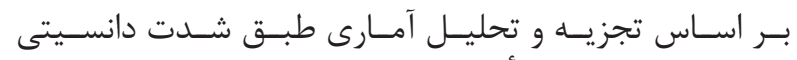

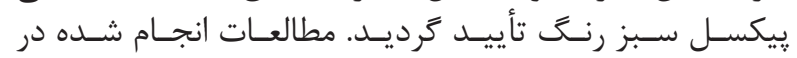

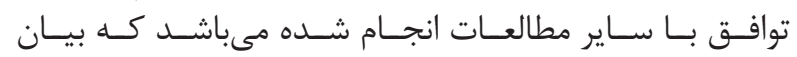

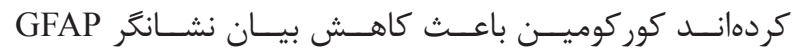

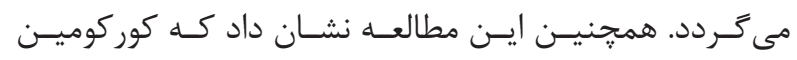

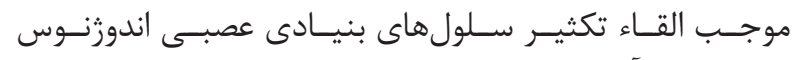

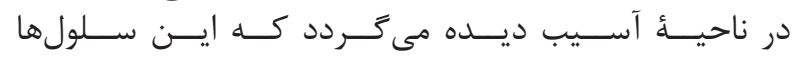

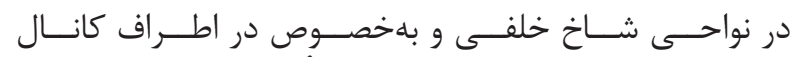

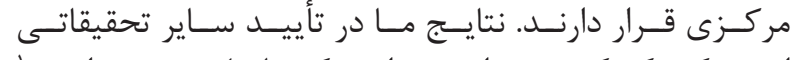

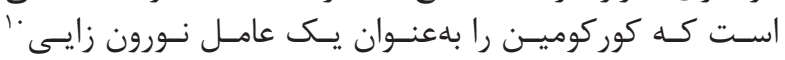

مىخوانــــد (\$ (\$).

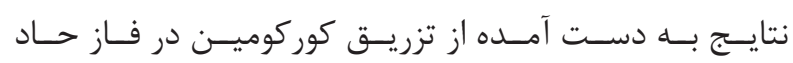

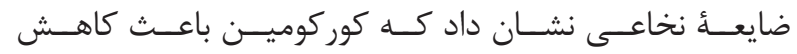

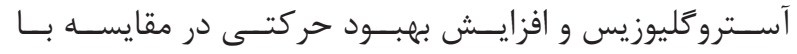

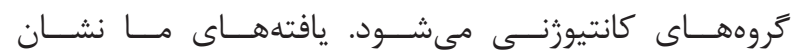

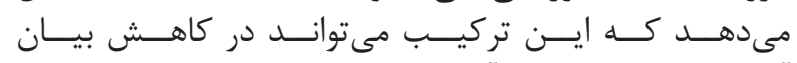

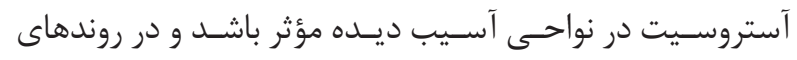

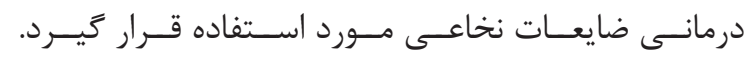

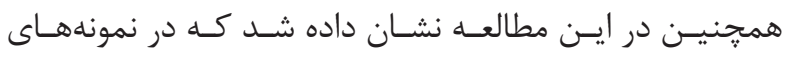

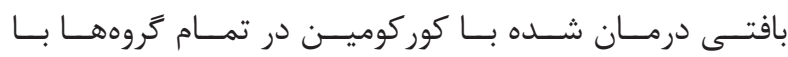

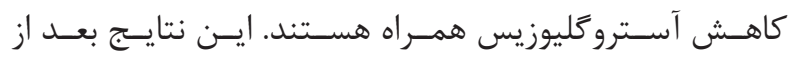

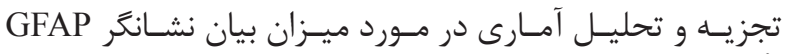

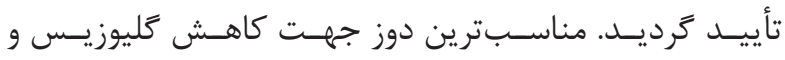

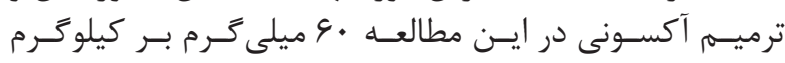

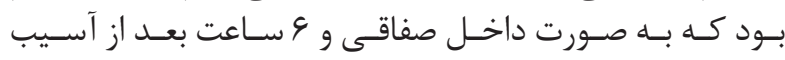

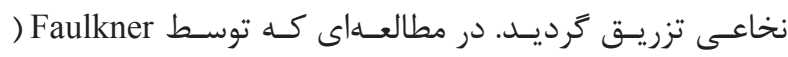

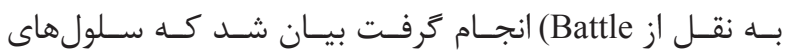

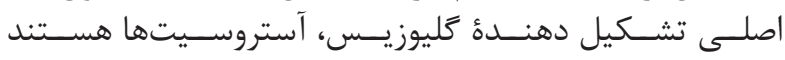

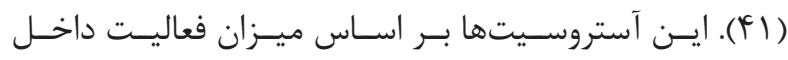

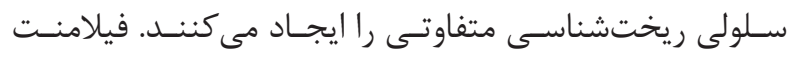

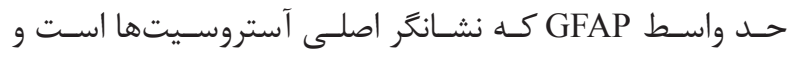

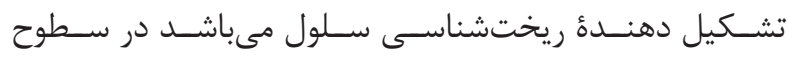

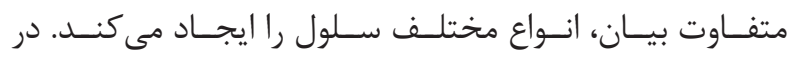

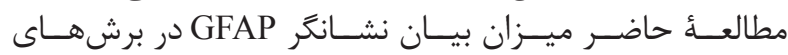

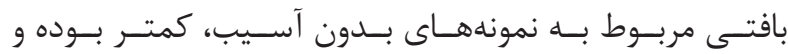

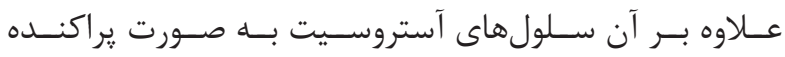

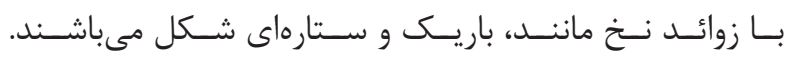

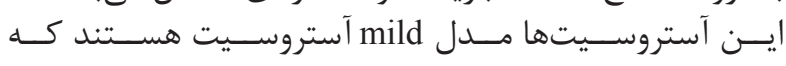

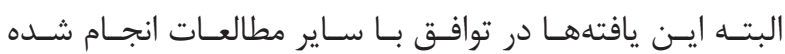

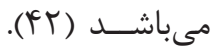

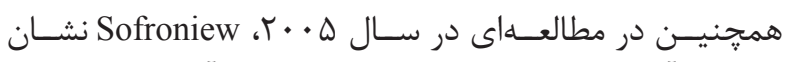

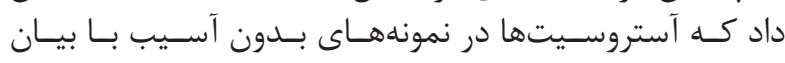

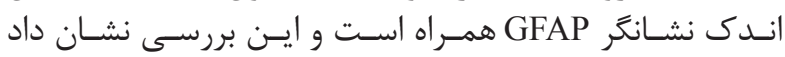

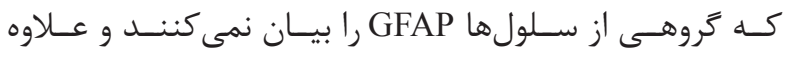

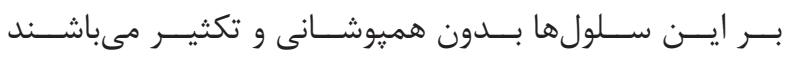

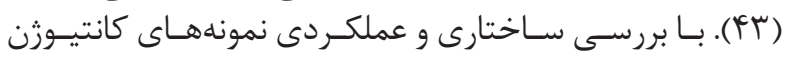

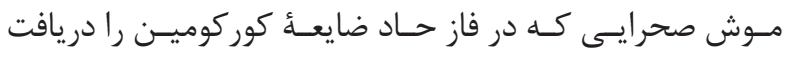

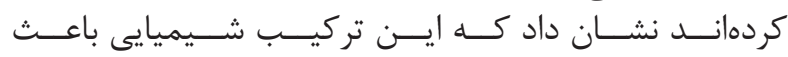


1. Fehlings MG, Vawda R. Cellular treatments for spinal cord injury: the time is right for clinical trials. Neurotherapeutics. 2011; 8(4): 704-20.

2. Ji W, Hu S, Zhou J, Wang G, Wang K, Zhang Y. Tissue engineering is a promising method for the repair of spinal cord injuries (Review). Exp Ther Med. 2014; 7(3): 523-8.

3. Lin B, Xu Y ,Zhang B, He Y, Yan Y, He M. MEK inhibition reduces glial scar formation and promotes the recovery of sensorimotor function in rats following spinal cord injury. Exp Ther Med. 2014; 7(1): 66-72.

4. Mothe A, Tator C. Advances in stem cell therapy for spinal cord injury. J Clin Invest. 2012; 122(11): 3824-34.

5. Adeeb N, Mortazavi M. The role of FGF2 in spinal cord trauma and regeneration research. Brain and Behavior. 2014; 4(2): 105-7.

6. Burda J, Sofroniew M. Reactive gliosis and the multicellular response to CNS damage and disease. Neuron. 2014; 81(2): 229-48.

7. Darvishi M, Tiraihi T, Taheri T. P62: the effect of valproic acid therapy on the glial scar formation after acute spinal cord injury fallowing by motor vehicle traffic crashes. Shefaye Khatam. 2015; 2(S3): 112.

8. Zhang N, Yin Y, Xu S, Wu Y, Chen W. Inflammation $\&$ apoptosis in spinal cord injury. Indian J Med Res. 2012; 135(3): 287-96.

9. Rodríguez-Barrera R. Immunization with a neuralderived peptide protects the spinal cord from apoptosis after traumatic injury. Bio Med Research International. 2013; 8: doi.org/10.1155/2013/827517.

10. Hall D. Antioxidant therapies for acute spinal cord injury. The Journal of the American Society for Experimental Neuro Therapeutics. 2011; 8(2): 152-67.

11. Kopp M, Liebscher T, Niedeggen A, Laufer S, Brommer B, Jungehulsing G, et al. Small-moleculeinduced Rho-inhibition: NSAIDs after spinal cord injury. Cell Tissue Res. 2013; 349(1): 119-32.

12. Aligholi H, Attari F, Modarres Mousavi M, Khodaie B. Traumatic brain injury and genes. Shefaye Khatam. 2015; 2(S3): 139.

13. Darvishi M, Tiraihi T, Taheri T. Treatment of spinal cord injury using transplantation of motoneurons derived from adipose stem cells following histone deacetylases inhibitors therapy in acute phase. Shefaye
Khatam. 2015; 2(S3): 114.

14. Becker D. Basic and clinical pharmacology of glucocorticosteroids. Anesth Prog. 2013; 60(1): 25-32.

15. Kanwar JR, Sriramoju B, Kanwar RK. Neurological disorders and therapeutics targeted to surmount the bloodbrain barrier. Int J Nanomedicine. 2012; 7: 3259-78.

16. Hurlbert RJ. The role of steroids in acute spinal cord injury: an evidence-based analysis. Spine (Phila Pa 1976). 2001; 26(24): S39-46.

17. Hawryluk GW, Rowland J, Kwon BK, Fehlings MG. Protection and repair of the injured spinal cord: a review of completed, ongoing, and planned clinical trials for acute spinal cord injury. Neurosurg Focus. 2008; 25(5): E14.

18. Tator $\mathrm{CH}$. Review of treatment trials in human spinal cord injury: issues, difficulties, and recommendations. Neurosurgery. 2006; 59(5): 957-82.

19. Jahanbazi Jahan-Abad, Ali, Parastoo Morteza-zadeh, Sajad Sahab Negah, Ali Gorji. Curcumin attenuates harmful effects of arsenic on neural stem/progenitor cells. AJP. 2017: 1-11.

20. Davis SJ, Khangure MS. A review of magnetic resonance imaging in spinal trauma. Australas Radiol. 1994; 38(4): 241-53.

21. Radojicic M, Nistor G, Keirstead HS. Ascending central canal dilation and progressive ependymal disruption in a contusion model of rodent chronic spinal cord injury. BMC Neurol. 2007; 7: 30.

22. Ohta K, Fujimura Y, Nakamura M, Watanabe M, Yato Y. Experimental study on MRI evaluation of the course of cervical spinal cord injury. Spinal Cord. 1999; 37(8): 580-4.

23. Arnold SA, Hagg T. Anti-inflammatory treatments during the chronic phase of spinal cord injury improve locomotor function in adult mice. J Neurotrauma. 2011; 28(9): 1995-2002.

24. Yu L, Fan Y, Ye G, Li J, Feng X, Lin K, et al. Curcumin inhibits apoptosis and brain edema induced by hypoxia-hypercapnia brain damage in rat models. Am J Med Sci. 2015; 349: 521-5.

25. Hu R, Zhou J, Luo C, Lin J, Wang X, Li X, et al. Glial scar and neuroregeneration: histological, functional, and magnetic resonance imaging analysis in chronic spinal cord injury. J Neurosurg Spine. 2010; 13: 169-80. 
26. Darvishi M, Tiraihi T, Taheri T. Decreased GFAP expression and improved functional recovery in contused spinal cord of rats following valproic acid therapy. Neurochem Res. 2014; 39: 2319-33.

27. Darvishi M, Tiraihi T, Taheri T. Depakine improve axonal growth in vitro and in vivo after spinal cord injury. Shefaye Khatam. 2015; 2(S3): 128.

28. Kavakli H, Koca C, Alici C. Ntioxidant effects of curcumin in spinal cord injury in rats. Ulus Travma Acil Cerrahi Derg. 2011; 17(1): 14-8.

29. Go HS. Valproic acid inhibits neural progenitor cell death by activation of NF-B signaling pathway and upregulation of Bcl-XL. J Biomed Sci. 2011; 18(1):48. doi: 10.1186/1423-0127-18-48.

30. Fitch MT, Doller C, Combs CK, Landreth GE, Silver J. Cellular and molecular mechanisms of glial scarring and progressive cavitation: in vivo and in vitro analysis of inflammation-induced secondary injury after CNS trauma. J Neurosci. 1999; 19(19): 8182-98.

31. Crowe MJ, Bresnahan JC, Shuman SL, Masters JN, Beattie MS. Apoptosis and delayed degeneration after spinal cord injury in rats and monkeys. Nat Med. 1997; 3(1): 73-6.

32. Liu D, Diorio J, Tannenbaum B, Caldji C, Francis D, Freedman A, et al. Maternal care, hippocampal glucocorticoid receptors, and hypothalamic-pituitaryadrenal responses to stress. Science. 1997; 277 (5332): 1659-62.

33. Jung G. Valproic acid induces differentiation and inhibition of proliferation in neural progenitor cells via the beta-catenin-Ras-ERK-p21Cip/WAF1 pathway. BMC Cell Biol. 2008; 9: 66. doi: 10.1186/1471-21219-66.

34. Bang W. Valproic acid increases expression of neuronal stem/progenitor cell in spinal cord injury. J Korean Neurosurg Soc. 2013; 54(1): 8-13.

35. Darvishi M, Tiraihi T, Taheri T. The repair effects of histone deacetylases inhibitors on improves locomotion: in vivo evaluation with electromyography (emg) after spinal cord injury. Shefaye Khatam. 2015; 2(S3): 129.
36. Toy D, Namgung Uk. Role of glial cells in axonal regeneration. Exp Neurobiol. 2013; 22(2): 68-76.

37. Wanner B, Deik A, Torres M, Rosendahl A, Neary JT, Lemmon VP, et al. A new in vitro model of the glial scar inhibits axon growth. Glia. 2011; 15; 56(15): 1691709.

38. Li HP. Roles of chondroitin sulfate and dermatan sulfate in the formation of a lesion scar and axonal regeneration after traumatic injury of the mouse brain. $\mathrm{J}$ Neurotrauma. 2013; 30(5): 413-25.

39. Wang H. Chondroitin-4-sulfation negatively regulates axonal guidance and growth. J Cell Sci. 2008; 121(Pt 18): 3083-91.

40. Jones EV, Bouvier D. Astrocyte-secreted matricellular proteins in cns remodelling during development and disease. Neural Plasticity. 2014; 2014: 12.

41. Battle. Ligand binding to the $(1 \rightarrow 3)-\beta$-d-glucan receptor stimulates nfib activation, but not apoptosis in u937 cells. Biochem Biophys Res Commun. 1998; 249(2): 499-504.

42. Aggarwal BB, Sung B. Pharmacological basis for the role of curcumin in chronic diseases: an age-old spice with modern targets. Trends Pharmacol Sci. 2009; 30(2): 85-94.

43. Sofroniew MV. Reactive astrocytes in neural repair and protection. Neuroscientist. 2005; 5: 400-7.

44. Sofroniew MV. Molecular dissection of reactive astrogliosis and glial scar formation. Trends Neurosci. 2009; 32(12): 638-47.

45. Song YJC, Halliday GM, Holton JL, Lashley T, O'Sullivan SS, McCann H, et al. Degeneration in different parkinsonian syndromes relates to astrocyte type and astrocyte protein expression. J Neuropathol Exp Neurol. 2009; 68(10): 1073-83.

46. Yagi Y. Effects of valproic acid on the cell cycle and apoptosis through acetylation of histone and tubulin in a scirrhous gastric cancer cell line. J Exp Clin Cancer Res. 2010; 29(1): 149. doi: 10.1186/1756-9966-29-149. 